Article

\title{
Diachronic UAV Photogrammetry of a Sandy Beach in Brittany (France) for a Long-Term Coastal Observatory
}

\author{
Marion Jaud ${ }^{1, *}\left(\mathbb{D}\right.$, Christophe Delacourt ${ }^{2}$, Nicolas Le Dantec ${ }^{2,3}$, Pascal Allemand ${ }^{4}$, \\ Jérôme Ammann ${ }^{2}$, Philippe Grandjean ${ }^{4}$, Henri Nouaille ${ }^{2}$, Christophe Prunier ${ }^{2}$, \\ Véronique Cuq ${ }^{5}$, Emmanuel Augereau ${ }^{6}$, Lucie Cocquempot ${ }^{2}$ and France Floc' ${ }^{2}{ }^{2}$ \\ 1 IUEM-UMS 3113, Université de Bretagne Occidentale, IUEM, CNRS, Technopôle Brest-Iroise, Rue Dumont \\ d'Urville, F-29280 Plouzané, France \\ 2 Laboratoire Géosciences Océans-UMR 6538, Université de Bretagne Occidentale, IUEM, CNRS, Technopôle \\ Brest-Iroise, Rue Dumont d'Urville, F-29280 Plouzané, France; christophe.delacourt@univ-brest.fr (C.D.); \\ nicolas.ledantec@univ-brest.fr (N.L.D.); jerome.ammann@univ-brest.fr (J.A.); \\ henri.nouaille@gmail.com (H.N.); christophe.prunier@univ-brest.fr (C.P.); \\ lucie.cocquempot@univ-brest.fr (L.C.); france.floch@univ-brest.fr (F.F.) \\ 3 Cerema, Direction Eau Mer et Fleuves, F-60280 Margny-lès-Compiègne, France \\ 4 Laboratoire de Géologie de Lyon: Terre, Planètes, Environnement-UMR 5276, Université de Lyon, \\ Université Claude Bernard Lyon 1, ENS Lyon, CNRS, F-69622 Villeurbanne, France; \\ pascal.allemand@univ-lyon1.fr (P.A.); philippe.grandjean@univ-lyon1.fr (P.G.) \\ 5 LETG-UMR 6554, Université de Bretagne Occidentale, IUEM, CNRS, Technopôle Brest-Iroise, rue Dumont \\ d'Urville, F-29280 Plouzané, France; Veronique.Cuq@univ-brest.fr \\ 6 OSU de La Réunion, Université de La Réunion, CS 92003, F-97744 Saint-Denis, France; \\ emmanuel.augereau@univ-brest.fr \\ * Correspondence: marion.jaud@univ-brest.fr; Tel.: 33-298-498-891
}

Received: 7 May 2019; Accepted: 5 June 2019; Published: 7 June 2019

\begin{abstract}
In the dual context of coastal hazard intensification and the growing number of stakes exposed to these hazards, coastal observatories are in demand to provide a structured framework dedicated to long-term monitoring. This article describes the drone-based photogrammetry monitoring performed since 2006 on Porsmilin Beach (Brittany, France) in the framework of the DYNALIT (Littoral and Coastline Dynamics) observatory, focusing on data quality and the consistency of long-term time series under the influence of multiple technological evolutions: Unmanned Aerial Vehicles (UAV) platforms with the arrival of electric multirotor drones, processing tools with the development of structure-from-motion (SfM) photogrammetry, and operational modes of survey. A study case is presented to show the potential of UAV monitoring to study storm impacts and beach resilience. The relevance of high-accuracy monitoring is also highlighted. With the current method, an accuracy of $3 \mathrm{~cm}$ can be achieved on the digital elevation model (DEM) and the orthophotograph. The question of the representativity and frequency of DEM time points is raised.
\end{abstract}

Keywords: UAV; SfM photogrammetry; coastal observatory; beach monitoring

\section{Introduction}

Coastal zones are exposed to both marine and terrestrial processes, as well as anthropogenic impacts. As a fragile interface subject to highly dissipative energetic processes, coastal zones can undergo fast morphological changes. Furthermore, coastal zones are highly exposed to several natural risks: submersion, erosion, pollution, and so forth. These coastal risks are increasing due to the combination of (i) the intensification of the natural hazards driven by a relative shortage of sediment stocks and global climate change, and (ii) the growing number of stakes exposed to coastal hazards. 
Shoreline change is the result of both natural and anthropogenic factors and occurs over a wide range of spatial and temporal scales. Coastal zone management, therefore, requires adequate monitoring to unravel this multiscale evolution [1,2]. It is essential to improve the knowledge and tools needed to understand and quantify the physical evolution of the coastal environment and the processes behind these morphological changes [3-7]. In this context, coastal observatories offer a structured framework for long-term monitoring in a coordinated and systematic manner [8-10]. Such observatories are valuable both for scientific research and to provide usable information for management decisions and coastal engineering policies.

DYNALIT, created in 2014, is the French National Observation Service of CNRS/INSU (French National Institute of the Universe Sciences) dedicated to long-term observation of the coastal dynamic (https://www.dynalit.fr/). The DYNALIT network involves 22 universities and regroups 36 observation sites distributed over the French metropolitan and ultramarine coastlines, covering a wide range of coastal environments. Among these coastal environments, sandy beaches are particularly challenging to monitor, as they feature rapid and sometimes high-amplitude morphological changes and continually adjust to numerous processes driving morphological changes.

This study focused on the site of Porsmilin, a sandy embayed beach in Brittany, which is a DYNALIT study site. This beach has been monitored since 2000 with monthly surveys of topographical cross-shore profiles measured by total station or real-time kinematic differential GPS (RTK DGPS) [11]. Two-dimensional cross-shore profiles have been followed by digital elevation models (DEMs) computed from Unmanned Aerial Vehicles (UAV) photographs since 2006 or from terrestrial laser scanner (TLS) point clouds collected since 2009 [12,13]. A video imagery system has also been set up, continuously collecting one image per hour (and up to four images per second) since 2014. Intensive field campaigns of hydrodynamic measurements were also carried out in 2014 and 2016 [14,15]. The DYNALIT observatory is compatible with the on-going evolution of methodologies, as well as the diversity of observation approaches.

The potential of the UAV photogrammetric technique for monitoring geomorphological changes and, particularly, the evolution of sandy beaches has been demonstrated for several years $[16,17]$. Nevertheless, with technological improvements in platforms, sensors, and processing algorithms occurring at a fast pace, the method has significantly evolved over the years. This article focuses more particularly on long-term UAV photogrammetry, including how the methodological evolutions have been incorporated into the monitoring protocol and how these operational changes affect the quality of the monitoring.

\section{Study Area}

Porsmilin Beach (Figure 1) is located at the entrance of the Bay of Brest in the Iroise Sea in Brittany, France, a macrotidal zone with semidiurnal and symmetrical tides and a mean spring tidal range of $5.7 \mathrm{~m}$. The Iroise Sea is a highly energetic environment, with annual and decadal significant wave heights of, respectively, 11.3 and $14.5 \mathrm{~m}$ in $110 \mathrm{~m}$ of water depth to the west of Brittany [18]. On the beach, the mean annual wave height is $0.5 \mathrm{~m}$, whereas storm waves are up to $2 \mathrm{~m}$ high [18]. Inland and to the north, Porsmilin Beach is backed by a brackish-water marsh that no longer communicates with the sea. To the east and west, it is flanked by orthogneiss cliffs of about $15 \mathrm{~m}$ in height and bounded by headlands extending offshore into rocky reefs that only allow incident waves from the southwest and act as obstacles for longshore sand transport [14].

The intertidal zone is around $200 \mathrm{~m}$ wide in the longshore direction. The median sediment grain size (D50) is $320 \mu \mathrm{m}$ [18], with significant cross-shore variability, including coarser sediments (D50 $\approx 700 \mu \mathrm{m}$ ) around the crest of intertidal bars and the existence of shingles on the upper beach which become uncovered during episodes of energetic hydrodynamic forcing [14]. 


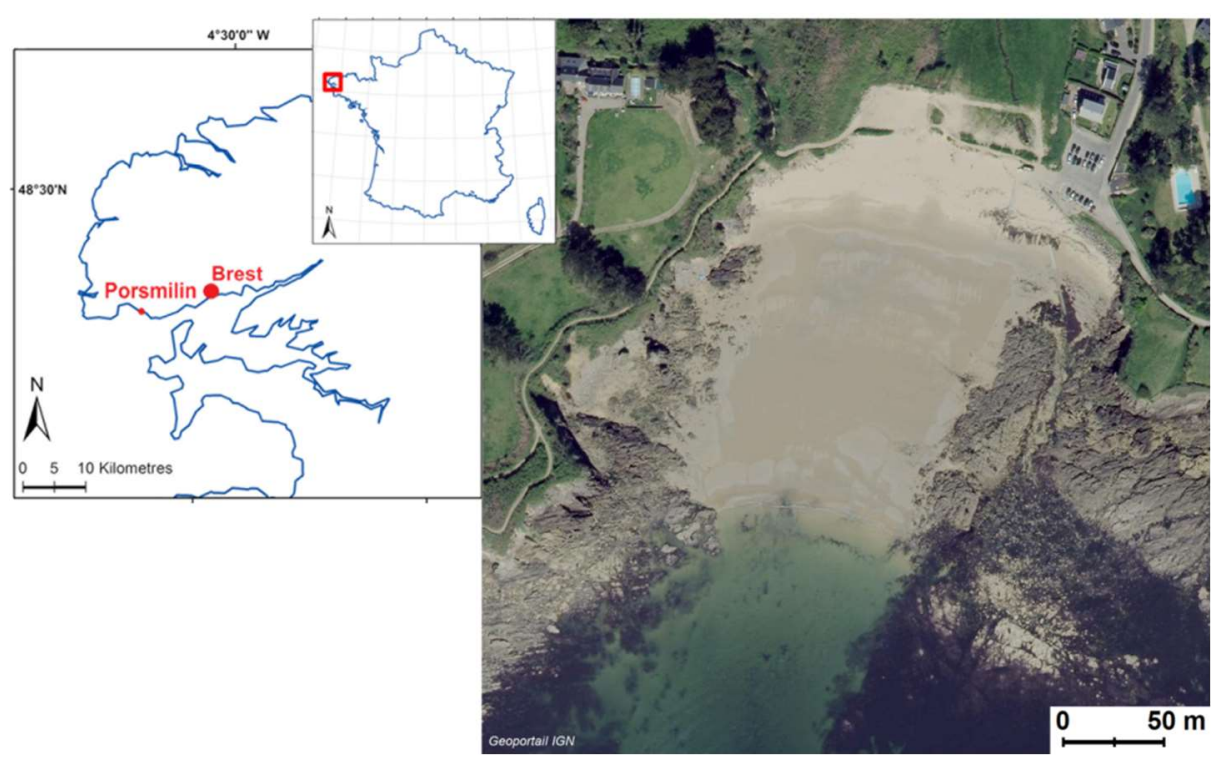

Figure 1. Location and orthophotograph of Porsmilin Beach (Geoportail IGN@-2015).

\section{Evolution of Technical Equipment and Methods}

\subsection{Evolution of the UAV Platforms}

The first UAV platform used above Porsmilin Beach was a Pixy ${ }^{\circledR}$ drone (Figure 2, Table 1), a model developed by the IRD (French Institute for Research and Development) and PHILAE concept ${ }^{\circledR}$ society [19]. It was a small radio-controlled paramotor, composed of a $3.8 \mathrm{~m}^{2}$ tubular fabric wing maintained by suspension lines. A tripod structure, suspended below the wing, supported a combustion engine of $25 \mathrm{~cm}^{3}$ and the sensors, including the camera (Fuji S2 Pro- $-50 \mathrm{~mm}$ ). The platform weighed $7 \mathrm{~kg}$ and had a maximum payload of $4 \mathrm{~kg}$. The flight was performed between 15 and $35 \mathrm{~km} / \mathrm{h}$. This model was used to perform surveys above Porsmilin Beach between 2006 and 2008. One of the main drawbacks of this system was the requirement of a wide area for takeoff and landing.

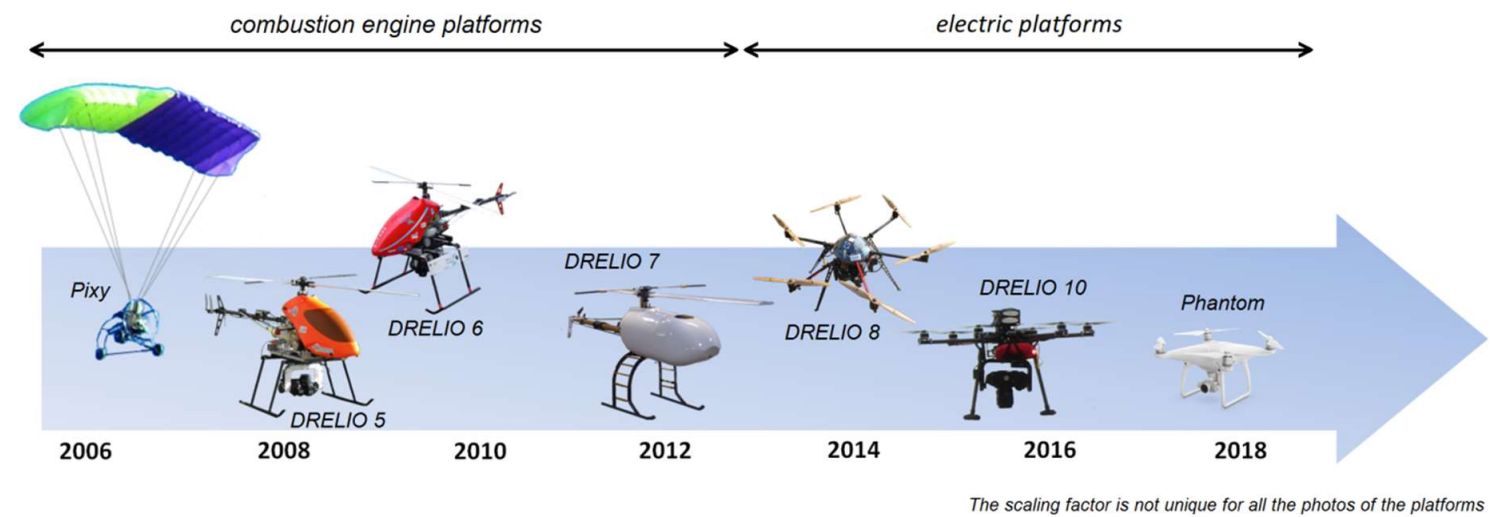

Figure 2. Evolution of the Unmanned Aerial Vehicles (UAV) platforms used for Porsmilin Beach monitoring.

From 2007 to 2012, three remote-controlled combustion engine helicopters (Figure 2, Table 1) were used for Porsmilin Beach monitoring. These UAV platforms, called DRELIO (DRone for Environmental and Littoral Observations), had been specifically adapted to coastal environments [16]: protection against corrosive salted air, ability to endure wind gusts, and so forth. These helicopters weighed around $10 \mathrm{~kg}$ with an additional payload of $5-8 \mathrm{~kg}$. The payload was modular, but for photogrammetric purposes, DRELIO helicopters were equipped with a commercial reflex camera (Nikon D200 at 10 Mpix and Nikon D700 at 12 Mpix), with a $35 \mathrm{~mm}$ focal length and parametrized in intervalometer mode. 
The autopilot was connected to an atmospheric pressure sensor, an inertial sensor, a geomagnetic direction sensor, and a GPS. DRELIO helicopters were capable of performing fully automatic takeoff and landing and following hovering flight plans [16]. The combustion engine enabled a flight autonomy of 45-50 min. Significant efforts had been made to limit vibrations, including reducing the rotation speed of blades or improving the stability of the camera gimbal. For DRELIO 7, the design was more industrialized and the structure was conceived with shock absorbers to isolate the payload from the motor vibrations.

Table 1. Main characteristics of the different UAV platforms used for Porsmilin Beach monitoring.

\begin{tabular}{|c|c|c|c|c|c|c|}
\hline \multirow{2}{*}{ Drone } & \multirow{2}{*}{$\begin{array}{l}\text { Operating } \\
\text { Period }\end{array}$} & \multicolumn{3}{|c|}{ Characteristics } & \multirow{2}{*}{ Camera } & \multirow{2}{*}{$\begin{array}{c}\text { Range of Mean } \\
\text { Accuracy }\end{array}$} \\
\hline & & Weight & Payload & Autonomy & & \\
\hline Pixy & 2006-2008 & $7 \mathrm{~kg}$ & $4 \mathrm{~kg}$ & $\sim 1 \mathrm{~h}$ & $\begin{array}{c}\text { Fuji S2 Pro, } \\
50 \mathrm{~mm}, 6 \text { Mpix }\end{array}$ & $10-20 \mathrm{~cm}$ \\
\hline DRELIO 5 & 2007-2010 & $11 \mathrm{~kg}$ & $5 \mathrm{~kg}$ & $45 \mathrm{~min}$ & $\begin{array}{c}\text { Nikon D200, } \\
35 \text { mm, } 10 \text { Mpix }\end{array}$ & $5-20 \mathrm{~cm}$ \\
\hline DRELIO 6 & 2010 & $9.5 \mathrm{~kg}$ & $5 \mathrm{~kg}$ & $45 \mathrm{~min}$ & $\begin{array}{c}\text { Nikon D200, } \\
35 \mathrm{~mm}, 10 \text { Mpix }\end{array}$ & $5-20 \mathrm{~cm}$ \\
\hline DRELIO 7 & 2012 & $15 \mathrm{~kg}$ & $8 \mathrm{~kg}$ & $50 \mathrm{~min}$ & $\begin{array}{c}\text { Nikon D700, } \\
35 \text { mm, } 12 \text { Mpix }\end{array}$ & $5-10 \mathrm{~cm}$ \\
\hline DRELIO 8 & 2013-2014 & $<4 \mathrm{~kg}$ & $1.5 \mathrm{~kg}$ & $15 \mathrm{~min}$ & $\begin{array}{c}\text { Nikon D700, } \\
35 \text { mm, } 12 \text { Mpix }\end{array}$ & $1-5 \mathrm{~cm}$ \\
\hline DRELIO 10 & 2015-2019 & $<4 \mathrm{~kg}$ & $1.5 \mathrm{~kg}$ & $15 \mathrm{~min}$ & $\begin{array}{c}\text { Nikon D800, } \\
35 \text { mm, } 36 \text { Mpix }\end{array}$ & $1-2 \mathrm{~cm}$ \\
\hline Phantom Pro & 2018-2019 & $1.4 \mathrm{~kg}$ & $0.3 \mathrm{~kg}$ & $25 \mathrm{~min}$ & $\begin{array}{c}\text { FC6310, } \\
8.8 \mathrm{~mm}, 20 \text { Mpix }\end{array}$ & $1-3 \mathrm{~cm}$ \\
\hline
\end{tabular}

Since 2013, the DRELIO platforms that have been used in Porsmilin Beach are electrical multirotors (Figure 2, Table 1): hexacopters (MikroKopter ${ }^{\circledR}$ and DroneSys DS6 ${ }^{\circledR}$ ) or quadcopters (DJI Phantom ${ }^{\circledR}$ ). Both hexacopters are almost the same, weighing less than $4 \mathrm{~kg}$ and being able to handle a payload of $1.5 \mathrm{~kg}$. Their actual flight autonomy is about $15 \mathrm{~min}$. The flight control is performed by the DJI ${ }^{\circledR}$ software iOSD. The payload is modular and, as before, for photogrammetric purposes, a commercial reflex camera (Nikon D700 at 12 Mpix or Nikon D800 at 36 Mpix) with a $35 \mathrm{~mm}$ focal length is used [20]. The Phantom 4 Pro drone weighs less than $1.5 \mathrm{~kg}$ (including batteries and camera). This inexpensive, ready-to-use system is also a highly integrated solution, limiting the possibilities of tuning the drone or the sensor. Now, DJI ${ }^{\circledR}$ proposes a Phantom 4 equipped with RTK positioning, but this model has not been tested at Porsmilin Beach yet.

Compared with the previous models, the multirotor platforms have shorter flight autonomy but are much easier to control and easier to transport. Furthermore, they induce fewer vibrations and allow more stable flights. With the first drone platforms, some parts of the study area were not covered by the photographs, resulting in incomplete DEMs and orthophotographs. The vibrations also caused blurring effects on certain photographs (Figure 3), which could make tie-point detection challenging. Further, these vibrations generated less stability of the inner orientation of the camera, which made correcting the associated systematic errors more difficult.

Autopilots have also evolved. The Pixy ${ }^{\circledR}$ drone was not equipped with an autopilot and was only remotely piloted. On the helicopter platforms, the system was designed for aerobatic aircraft models. The operator had to parametrize the speed of the drone and the camera intervalometer as a function of the flight height and the desired overlap, with the problem of stability loss at very low speed. Between 2006 and 2014, the flight plan was parametrized to achieve along-track and across-track overlap of around $60 \%$. Since 2015, the along-track overlap has been increased to 80\%. With the Phantom drone, as the autopilot is designed for photogrammetric applications, the overlap is directly parametrized in the flight plan. 


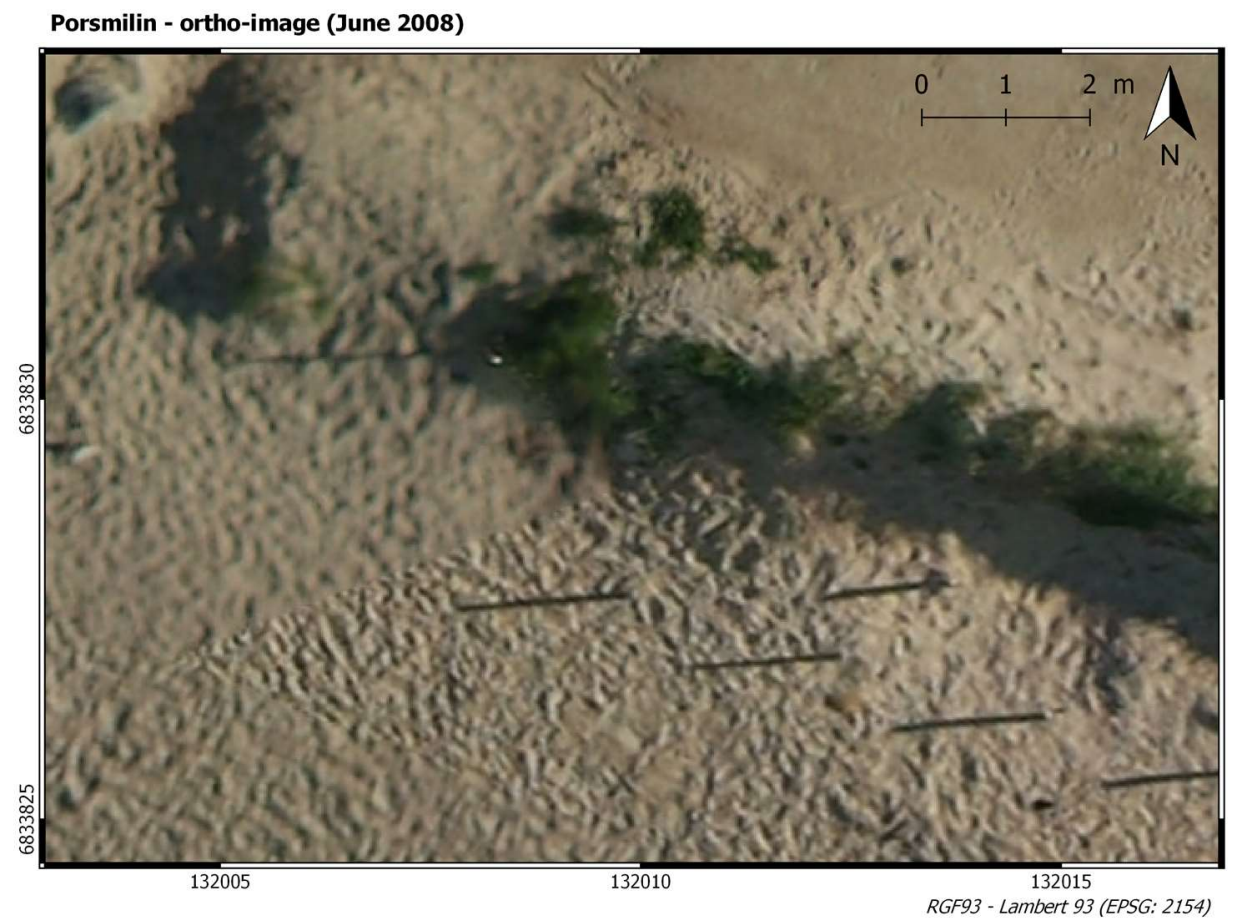

Figure 3. Portion of an orthoimage illustrating the variation in photograph quality during a flight performed in June 2008 with the Pixy ${ }^{\circledR}$ drone.

\subsection{Evolution of the Processing Tools}

Originally, data processing was performed using codes written with Matlab ${ }^{\circledR}$ software. The inner orientation and lens distortion parameters of the camera were predetermined from a series of photographs collected before the survey above a grid pattern of georeferenced targets in such a way that the targets were visible in different parts of the images (Figure 4). The stereorestitution algorithms were based on classical photogrammetric techniques [16].
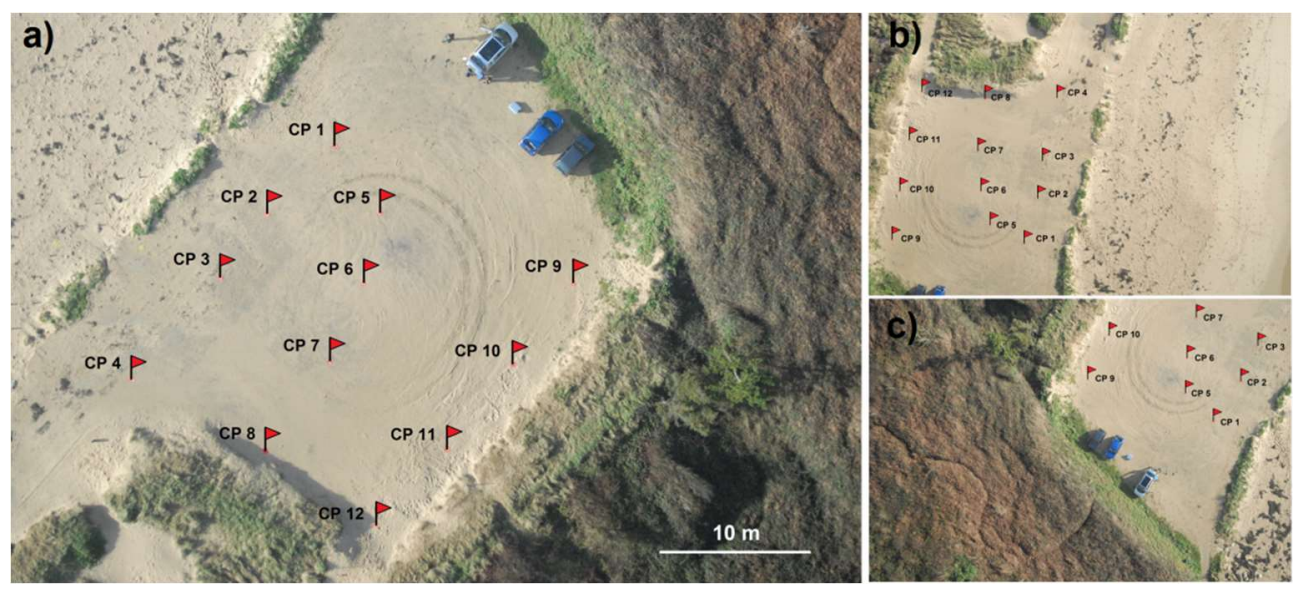

Figure 4. Examples of photographs collected by DRELIO 5 in February 2009 above the grid pattern of targets for camera calibration.

During the last decade, stereophotogrammetric processing has largely evolved with the development of the structure-from-motion ( $\mathrm{SfM}$ ) technique. This method, based on computer vision concepts, solves automatically and simultaneously the camera self-calibration and scene geometry using image matching and bundle adjustment. SfM photogrammetry is therefore less constraining for the camera calibration, which simplifies the in situ survey protocol. At the same time, the generalization 
of the scale-invariant feature transform (SIFT) algorithm [21] has changed the approach of tie-point detection, enabling scale- and rotation-invariant image matching.

In the context of these methodological developments, photogrammetric software tools have been popularized, accompanying a growing use of photogrammetry outputs for many applications. Many open-source and commercial solutions are now proposed. On the Porsmilin Beach study site, we mainly used Agisoft PhotoScan Pro ${ }^{\circledR}$ software, and occasionally MicMac ${ }^{\circledR}$, the free open-source software produced by IGNC (the French National Institute of Geographic and Forest Information). For consistency, all the former surveys of the observatory datasets were reprocessed using PhotoScan ${ }^{\circledR}$, following the same protocol.

\subsection{Evolution of the Survey Operational Mode}

The DYNALIT Observation Service encompasses a great diversity of sites (in view of their type, their size, the implied hydrodynamic processes, etc.). Various survey methods are therefore implemented depending on the observation site. For Porsmilin Beach, the evolution in equipment and processing tools has induced an evolution of the survey operational mode.

Regardless of the survey platform, acquisition protocol, and processing tools, ground control points (GCPs) are essential in the photogrammetric process to attain centimetric accuracy [16,22-24]. Therefore, this issue has been received much attention. As the beach is permanently changing, it is not possible to use fixed GCPs. Instead, different kinds of removable targets have been tested as GCPs (Figure 5). These targets have to be highly visible on the beach with various illumination conditions. They also need to be sand and water resistant, easy to transport, and low cost. For example, the light green and orange square plastic targets $(33 \times 33 \mathrm{~cm})$ used for the first surveys of Porsmilin Beach (Figure 5a,b) were sometimes difficult to detect in the photographs. Currently, GCPs consist of red plastic plates that are $30 \mathrm{~cm}$ in diameter (Figure $5 \mathrm{c}$ ), which can be secured with pegs in case of wind or wave surge. Monochromic targets have been chosen because they appear to be easier to detect on the upper part of the beach, which is highly reflective in sunny weather. Furthermore, the red color rarely occurs in natural environments and strongly contrasts with pale or bright sand.

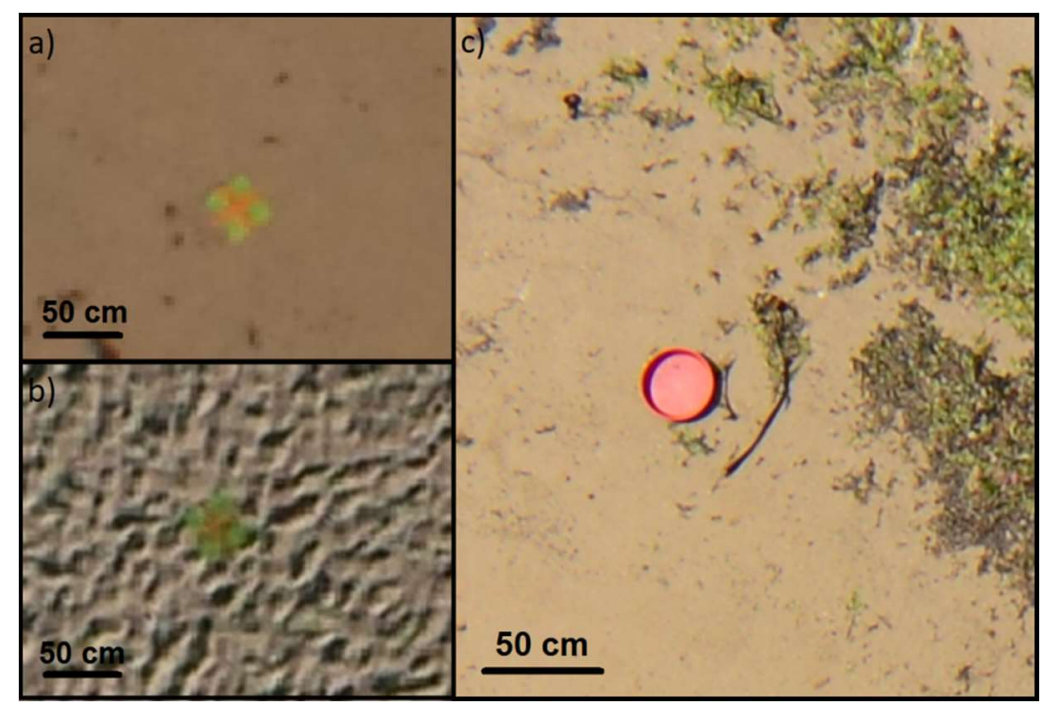

Figure 5. Examples of the different types of targets used as ground control points (GCPs): (a,b) light green and orange square plastic targets with varying illumination conditions (photos respectively taken in 2006 and 2008); (c) $30 \mathrm{~cm}$ red plastic plate currently used (photo taken in 2015).

The deployment and positioning of the targets is the most time-consuming step of the survey process. The flexibility of SfM photogrammetry, particularly with the benefits of self-calibration, 
compared with classical photogrammetry allows using a limited number of GCPs. However, it is still critical to optimize the geometry of the GCP network in order to avoid geometric distortion [23-25].

The method used to accurately measure GCP location has also changed. Since 2006, GCPs have been surveyed by RTK DGPS most of the time, and occasionally with a total station. Originally, the GPS base antenna was situated $900 \mathrm{~m}$ away from the beach. As the measurement accuracy decreases with the distance between base antenna and rover antenna, a new topographic marker for the GPS base station position was set up near Porsmilin Beach in 2010. To ensure continuity and redundancy in the quality of GCP measurements, three control points, also marked by topographic nails, are located close to the beach. In 2010, the reference coordinate system was switched from NGF-Lambert 1 to RGF 93-Lambert 93, which is currently the official coordinate system in France. All the first GPS point files have since been converted to RGF 93-Lambert 93 using the reference IGN ${ }^{\circledR}$ Circé converter tool. When the former surveys of the observatory datasets were reprocessed using PhotoScan ${ }^{\circledR}$ to ensure consistency, the converted GPS point files (in RGF 93-Lambert 93) were used for GCP locations in data reprocessing.

\section{Results and Discussion}

\subsection{Data Quality}

Changes to the survey equipment, protocols, and data processing have been made over time with the objective of optimizing the consistency of the dataset series. When possible, in particular for processing steps, the earlier datasets were reprocessed using the same workflow. Still, the quality of the oldest datasets is lower than the quality currently attained. The improvement of quality with time is due to various factors, such as: (i) the technological evolutions of the platform (allowing more flexibility in flight plan designing and more stability in flight), (ii) the technological evolutions of the sensors (allowing higher spatial resolution), (iii) higher accuracy in GCP measurement, and (iv) improvements in the survey protocol (for example, an optimization of the GCP network). These evolutions have driven the monitoring strategy of the observatory for Porsmilin Beach regarding the choice of survey instrumentation and methods. Until 2009, UAV photogrammetry was the only method available in the observatory to conduct very high resolution surface surveys over large areas. With the acquisition of TLS in 2009, UAV surveys became more scattered, as TLS surveys were, at that time, more accurate, easier to organize, and easier and quicker to process. Since 2014-2015, with the aforementioned evolutions, UAV photogrammetry is somewhat superseding TLS surveys in the data acquisition strategy of the observatory.

Ideally, the quality of the dataset is assessed using some georeferenced targets as control points rather than GCPs. In the dataset of June 2015, which is representative of current datasets, the root-mean-square error (RMSE) was lower than $3 \mathrm{~cm}$ (using 12 GCPs and calculating errors on 16 validation points). For several datasets where all the targets were used as GCPs because the GCP network was not optimal, the quality is difficult to evaluate. In such cases, the accuracy of the DEM and the orthophotograph is assessed by comparing the position of some remarkable points in the study area (e.g., rocks, boat ramp, or car park) with their position on a dataset with the highest accuracy (here, June 2015). However, this method only provides a first-order error assessment based on very few points located on the edge of the study area, where image overlapping is not as good as on the beach itself. Among the oldest datasets (from 2006 to 2008), the mean accuracy is about 10-15 cm, with errors sometimes up to $90 \mathrm{~cm}$ on certain parts of the DEM with poor photograph overlap or poor tie-point distribution.

\subsection{Benefits of DEM Surveys}

In the context of the coastal observatory, the DEM and the orthophotograph provide richer spatial information than cross-shore profiles. Indeed, they enable to capture cross-shore movements but also long-shore variations of the beach morphology, such as beach cusps (Figure 6). Moreover, they allow 
a multiscale approach, from the study of the whole beach to the morphodynamics of smaller-scale sedimentary structures. Above all, the computation of DEMs of differences (DoDs), corresponding to grids of changes in elevation that occurred between two acquisition dates, provides a diachronic evolution of the entire beach. From these DoDs, sedimentary budgets can be computed with better spatial representativity than from GPS profiles.
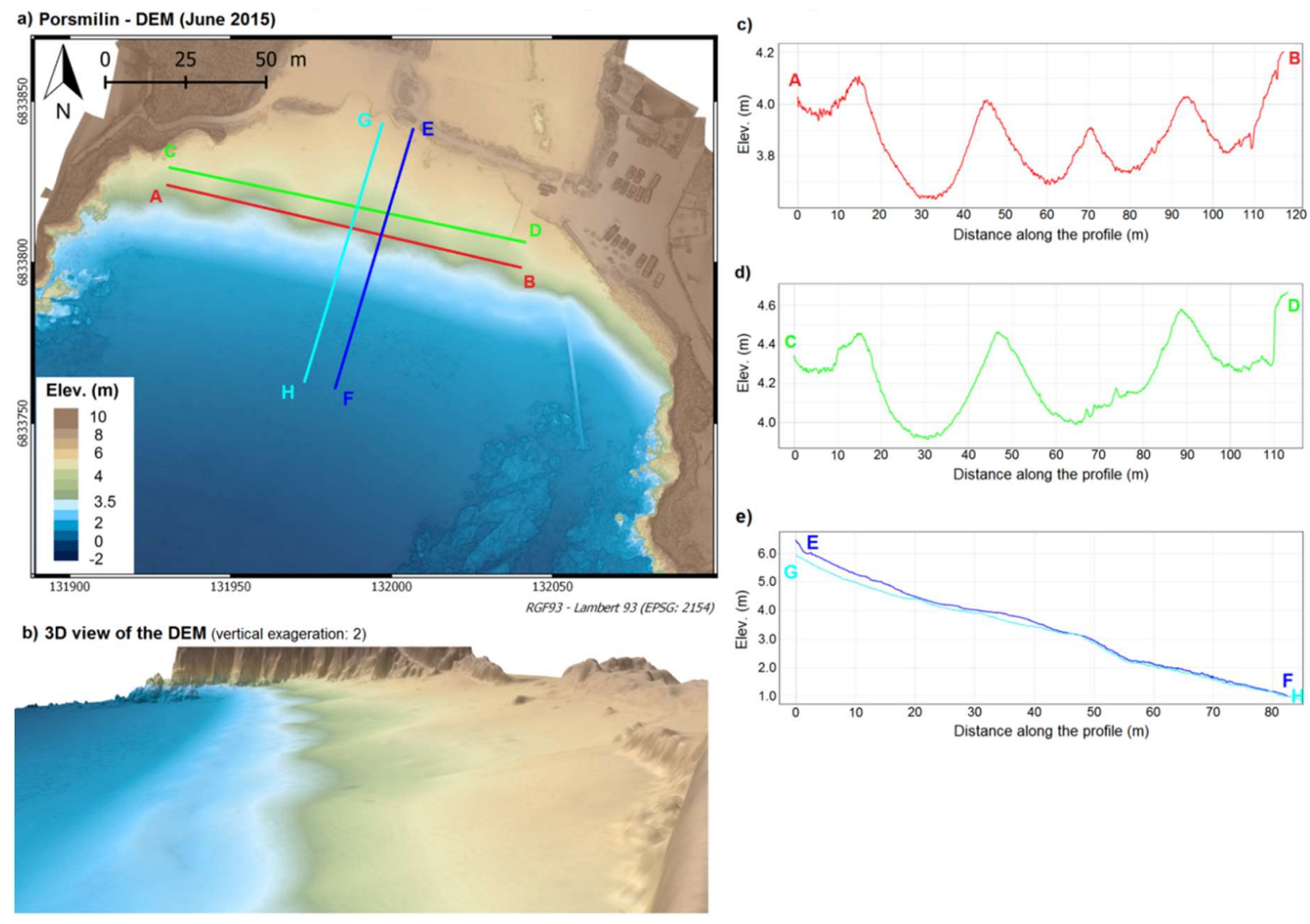

e)

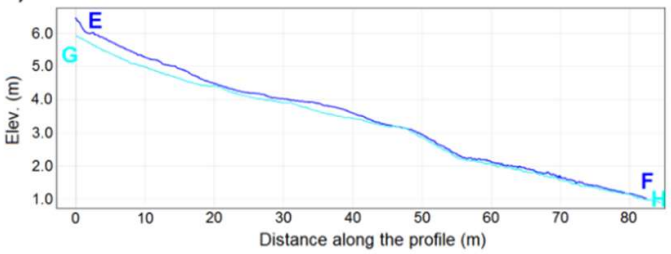

Figure 6. (a) Portion of the digital elevation model (DEM) computed from the photographs collected on the 16 June 2015. (b) 3D view of the DEM showing the beach cusps (vertical exageration: 2). (c,d) Alongshore beach vertical profiles showing the beach cusp morphology. (e) Cross-shore profiles showing differences in beach face gradient between embayments and horns.

\subsection{Study of Beach Resilience Following a Major Storm}

Figure 7 presents an example illustrating the relevance of UAV datasets for coastal observation and, particularly, studying beach resilience. During winter 2013-2014, successive storms hit Western Europe [26-28] causing severe erosion and submersion damage. A UAV dataset was collected in Porsmilin in February 2014, just after a series of storms: Petra (2014/02/04-05), Quimaira (2014/02/06-07), Ruth (2014/02/08), Tini (2014/02/12), and Ulla (2014/02/14). The morphology of the upper section of Porsmilin Beach was deeply altered, provoking a coastline retreat up to $18 \mathrm{~m}$ [29]. The orthophotograph and the DoD show this evolution, providing evidence of the water levels attained during storms and allowing computation of sediment budgets. The comparison of the orthophotographs of March 2012 (Figure 7a), February 2014 (Figure 7b), and June 2015 (Figure 7c) shows that the coastline position and the back-beach facilities were deeply and durably modified. Table 2 shows the pairwise differential sediment balance and normalized mean volume change evaluated between the three survey dates and over the computation zone $\left(5360 \mathrm{~m}^{2}\right.$, represented in Figure $\left.7 \mathrm{~d}-\mathrm{f}\right)$. Considering the spatial distribution of the sediment budget provided by the DoDs, it appears that the erosion mainly occurred on the upper shore, where the coastline had retreated. On the beach itself, the erosion that occurred during the storm was balanced by new sediment deposits, confirming the tendency of the beach to return to its equilibrium state. 

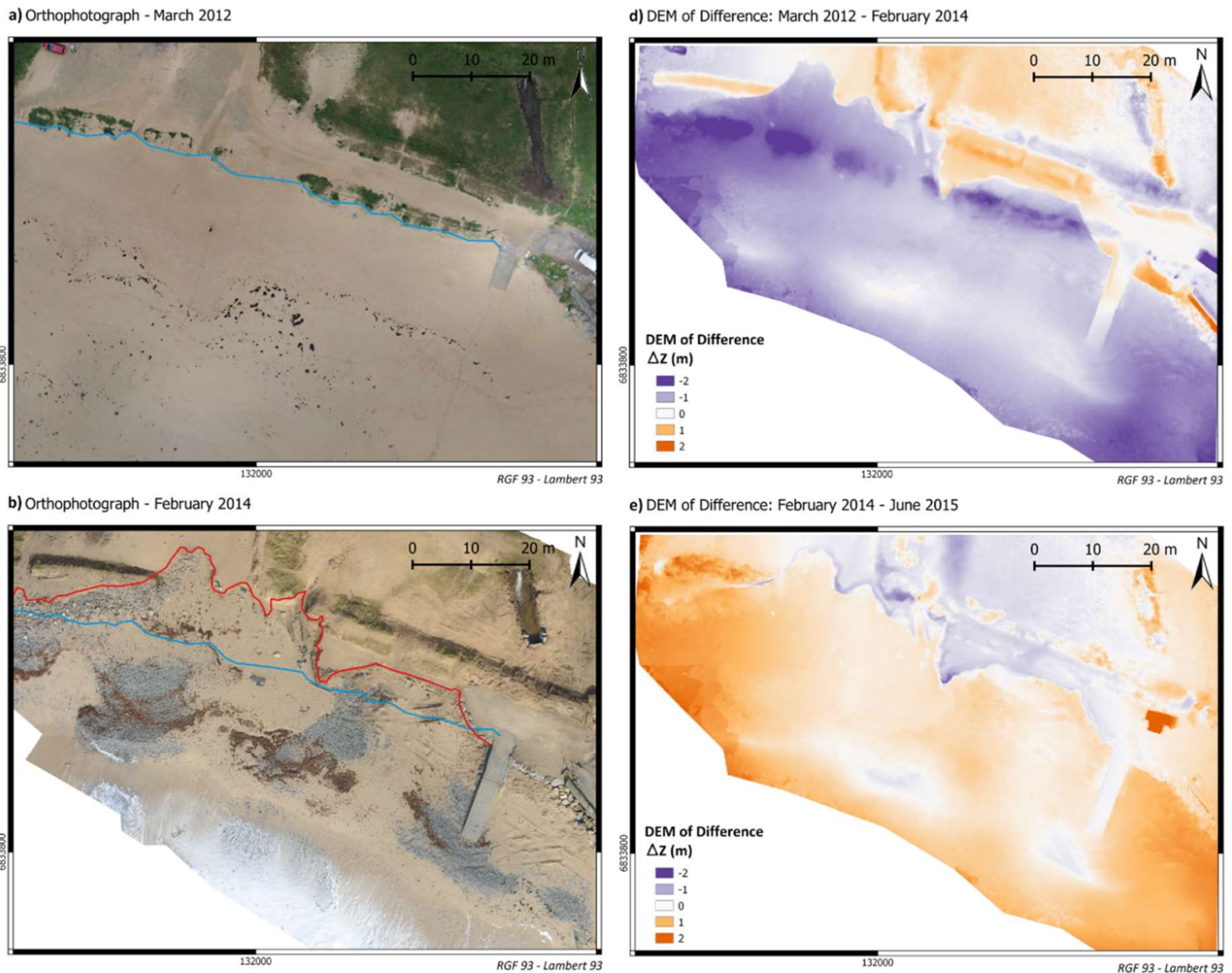

e) DEM of Difference: February 2014 - June 2015
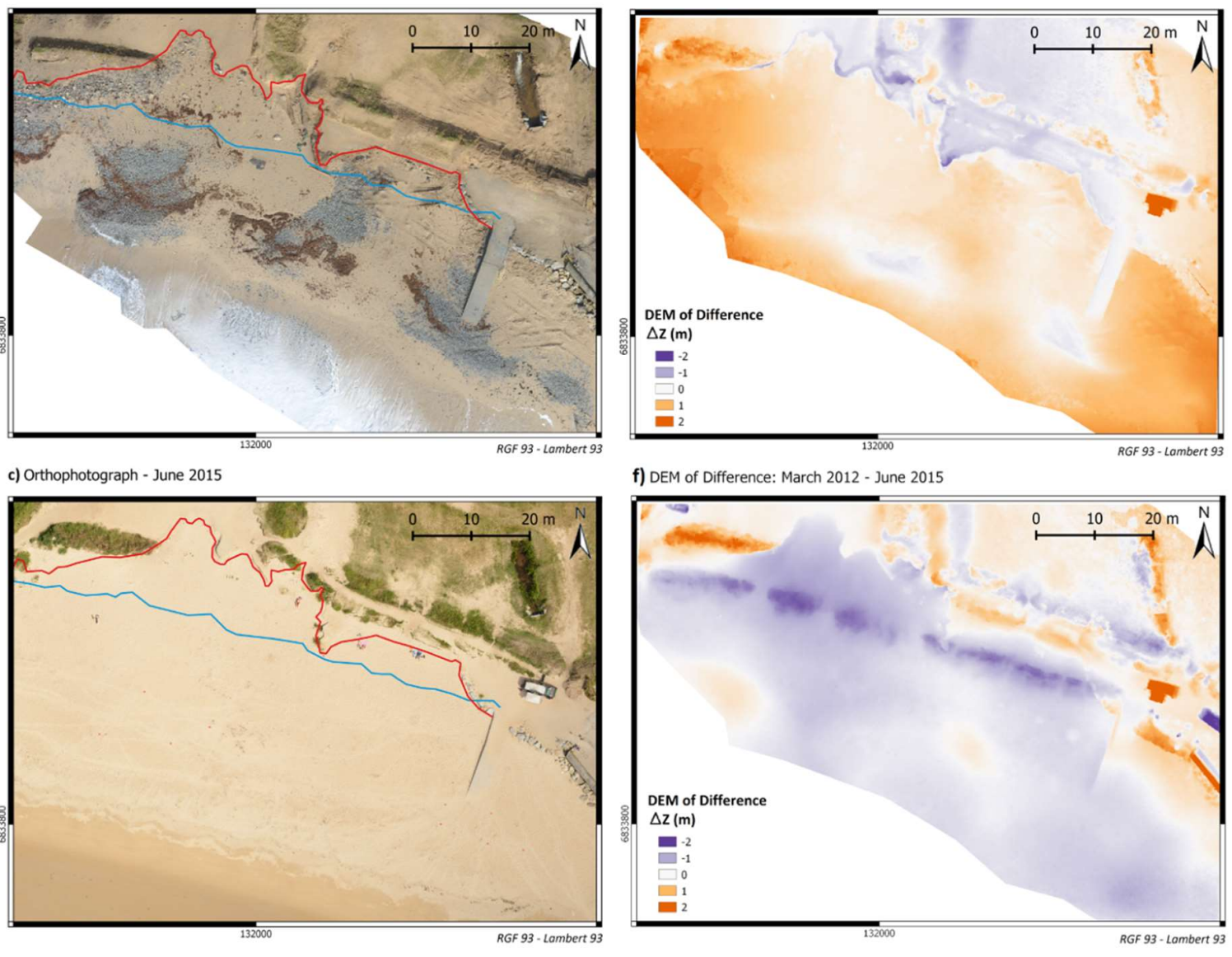

Figure 7. Use of orthophotographs and DoDs to study the impact of the storms (winter 2013-2014). Comparison of the orthophotographs in March 2012 (a), February 2014 (b), and June 2015 (c). DEM of differences computed over the periods from March 2012 to February 2014 (d), February 2014 to June 2015 (e), and March 2012 to June 2015 (f).

Table 2. Pairwise differential sediment balance and normalized mean volume change.

\begin{tabular}{ccc}
\hline DEMs of Differences (DoDs) & Sediment Budget $\left(\mathbf{m}^{3}\right)$ & $\begin{array}{c}\text { Normalized Mean Volume Change } \\
\left(\mathbf{m}^{3} / \mathbf{m}^{2}\right)\end{array}$ \\
\hline March 2012-Feb 2014 & $3005 \mathrm{~m}^{3}\left( \pm 536 \mathrm{~m}^{3}\right)$ & $-0.56 \mathrm{~m}^{3} / \mathrm{m}^{2}$ \\
Feb 2014-June 2015 & $2002 \mathrm{~m}^{3}\left( \pm 536 \mathrm{~m}^{3}\right)$ & $+0.37 \mathrm{~m}^{3} / \mathrm{m}^{2}$ \\
\hline
\end{tabular}


The DoD between March 2012 and March 2017 (Figure 8) enabled observation of the resilience of Porsmilin Beach over a longer period. Being both created from datasets of March, the DEMs considered in the computation of this $\mathrm{DoD}$ were chosen to minimize the impact of seasonal effects on this long-term sedimentary budget. The sediment balance was an erosion of $-2650 \mathrm{~m}^{3}\left( \pm 1708 \mathrm{~m}^{3}\right)$ over an area of $17,083 \mathrm{~m}^{2}$, which corresponded to a normalized mean erosion of $-0.15 \mathrm{~m}^{3} / \mathrm{m}^{2}\left( \pm 0.10 \mathrm{~m}^{3} / \mathrm{m}^{2}\right)$.

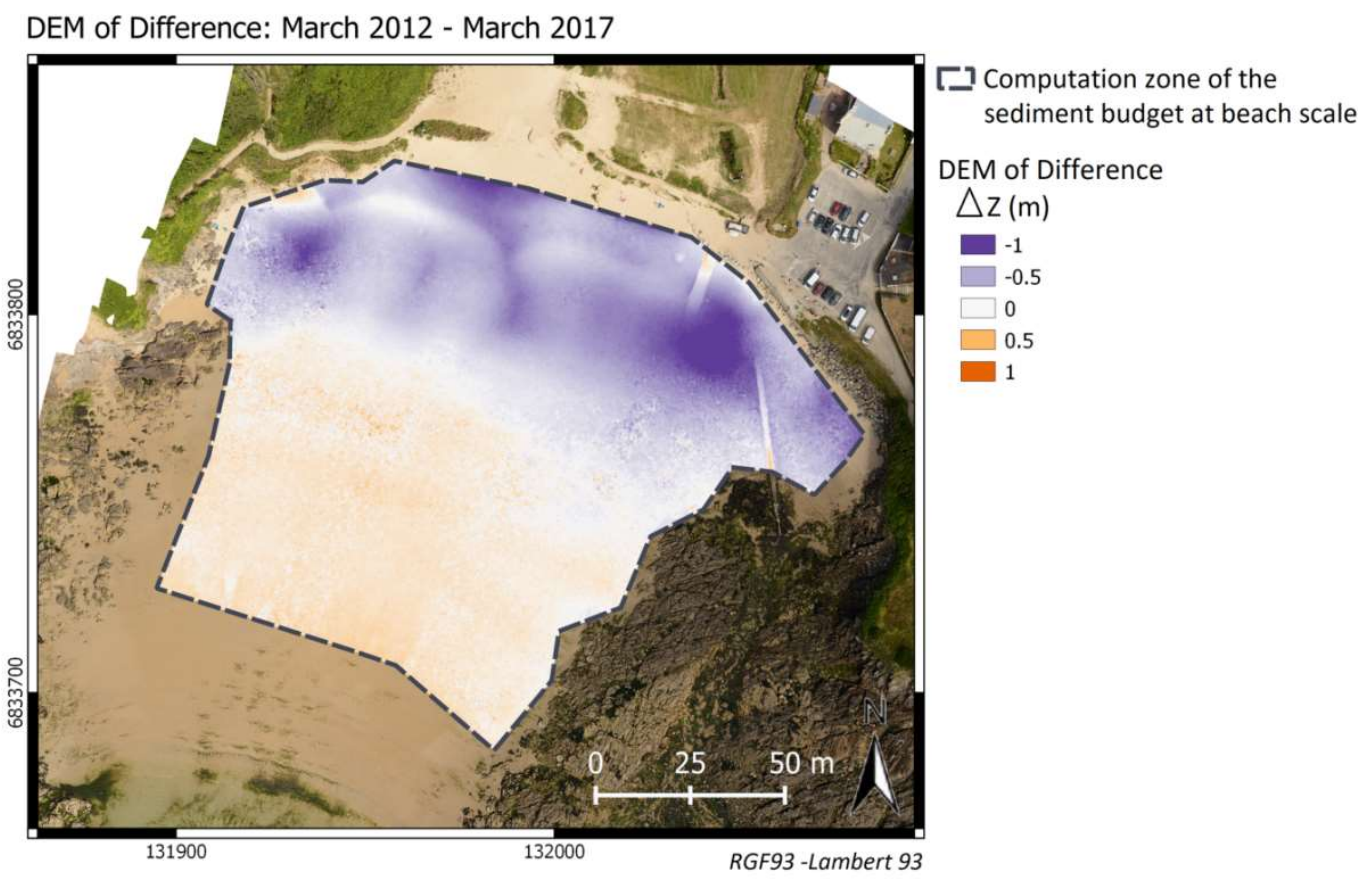

Figure 8. DoDs over the period from March 2012 to March 2017.

Such orders of magnitude in sediment budgets point out the importance of producing high-accuracy monitoring in order to limit the error margins. Furthermore, this example raises several questions about the influence of various parameters, notably, the prior beach state, the proportion of the change in sediment budget that is due to recent variations (during the last few days) or the influence of the dates of survey, and the period considered in the DoD. In Porsmilin Beach, the goal is to produce at least two high-resolution DEMs per year combining UAV and TLS surveys, so as to capture winter and summer periods, as in [30]. For a long-term observatory, despite the flexibility offered by UAV surveys nowadays, it seems difficult, both in terms of the time required for data acquisition and processing and of the required storage capacities, to carry out more than two or three flights per year, especially if more than one site is being monitored. Furthermore, UAV datasets can be combined with other datasets with high spatial resolution and accuracy, such as TLS surveys, which are less restrictive in terms of regulation but more restrictive in terms of spatial coverage.

It appears, therefore, relevant to complement these 3D monitoring techniques to allow capturing spatialized information and high spatial resolution with other monitoring techniques, which would allow capturing smaller temporal-scale morphological variations, such as cross-shore GPS profiles [31] or video imagery systems [32]. Beach profiling indeed enables high repeatability, even in response to storm events. Combining these techniques bridges the observational gap between spatial and temporal resolution and offers a synoptic vision of beach evolution.

\section{Conclusions}

With drone photographs being collected above Porsmilin Beach since 2006, this long-term monitoring has undergone evolutions in the aircrafts and embedded cameras used as well as an evolution in the processing chain, notably with the emergence of SfM photogrammetry. In parallel, the in situ survey protocol has evolved, drawing from experience but also taking advantage of these 
technological evolutions. The survey method currently used allows achieving an accuracy of $3 \mathrm{~cm}$ (horizontally and vertically) on the DEM and the orthophotograph. UAV photogrammetry appears, therefore, suitable for coastal morphodynamics survey in the context of a long-term observatory. Indeed, it enables rapid acquisition of 3D topographic data at high spatial resolution and low cost. Since the spatial resolution and accuracy are similar to TLS surveys, both monitoring techniques can be equally used, combined, and/or compared. Nevertheless, in a highly dynamic environment, such as a sandy beach, this type of monitoring needs to be combined with monitoring techniques that can capture high-frequency changes, such as GPS profiles or video monitoring.

With the development of drones using RTK GNSS for image geotagging, the survey protocol of Porsmilin Beach will keep evolving in the years to come. This precision positioning will enable a significant reduction in the number of GCPs or even eliminate the need for GCPs, saving time during the in situ survey and the processing step.

Author Contributions: Conceptualization, M.J., C.D., and P.A.; Methodology and Validation, M.J.; Investigation, M.J., J.A., P.G., C.P., V.C., and E.A.; Formal Analysis, M.J. and H.N.; Supervision, N.L.D. and F.F.; Project Administration, L.C.; Writing, M.J. and N.L.D.

Funding: This work is part of the "Service National d'Observation" DYNALIT, via the research infrastructure ILICO. The authors acknowledge financial support provided by ANR project EQUIPEX CRITEX (ANR-11-EQPX-0011). This work was also supported by ISblue project, interdisciplinary graduate school for the blue planet (ANR-17-EURE-0015) and LabexMER project (ANR-10-LABX-19), both funded by the French government (Agence Nationale de la Recherche) under the program "Investissements d'Avenir".

Conflicts of Interest: The authors declare no conflict of interests.

\section{References}

1. Baily, B.; Nowell, D. Techniques for monitoring coastal change: A review and case study. Ocean Coast. Manag. 1996, 32, 85-95. [CrossRef]

2. Klemas, V. Airborne Remote Sensing of Coastal Features and Processes: An Overview. J. Coast. Res. 2013, 287, 239-255. [CrossRef]

3. Howd, P.A.; Birkemeier, W.A. Beach and Nearshore Survey Data: 1981-1984 CERC Field Research Facility; Technical Report CERC-87-9; US Army Engineer Waterways Experiment Station: Vicksburg, MS, USA, 1987.

4. Stive, M.J.F.; Aarninkhof, S.G.J.; Hamm, L.; Hanson, H.; Larson, M.; Wijnberg, K.M.; Nicholls, R.J.; Capobianco, M. Variability of shore and shoreline evolution. Coast. Eng. 2002, 47, 211-235. [CrossRef]

5. Miller, P.; Mills, J.; Edwards, S.; Bryan, P.; Marsh, S.; Mitchell, H.; Hobbs, P. A robust surface matching technique for coastal geohazard assessment and management. ISPRS J. Photogramm. Remote Sens. 2008, 63, 529-542. [CrossRef]

6. Long, N.; Millescamps, B.; Guillot, B.; Pouget, F.; Bertin, X. Monitoring the Topography of a Dynamic Tidal Inlet Using UAV Imagery. Remote Sens. 2016, 8, 387. [CrossRef]

7. Letortu, P.; Jaud, M.; Grandjean, P.; Ammann, J.; Costa, S.; Maquaire, O.; Davidson, R.; Le Dantec, N.; Delacourt, C. Examining high-resolution survey methods for monitoring cliff erosion at an operational scale. GISci. Remote Sens. 2017, 1-20. [CrossRef]

8. Suanez, S.; Garcin, M.; Bulteau, T.; Rouan, M.; Lagadec, L.; David, L. Les observatoires du trait de côte en France métropolitaine et dans les DOM. EchoGéo 2012, 19. [CrossRef]

9. Nicholls, R.J.; Townend, I.; Bradbury, A.P.; Ramsbottom, D.; Day, S.A. Planning for long-term coastal change: Experiences from England and Wales. Ocean Eng. 2013, 71, 3-16. [CrossRef]

10. Mahabot, M.-M.; Jaud, M.; Pennober, G.; Le Dantec, N.; Troadec, R.; Suanez, S.; Delacourt, C. Toward a shoreline evolution observatory in tropical environments: The case of back-reef beaches in La Réunion Island. Comptes Rendus Geosci. 2017, 349, 330-340. [CrossRef]

11. Dehouck, A. Morphodynamique des plages sableuses de la mer d'Iroise (Finistère). Ph.D. Thesis, Université de Bretagne Occidentale, Brest, France, 2006. (In French).

12. Jaud, M. Techniques d'observation et de mesure haute résolution des transferts sédimentaires dans la frange littorale. Ph.D. Thesis, Université de Bretagne Occidentale, Brest, France, 2011. (In French). 
13. Jaud, M.; Letortu, P.; Augereau, E.; Le Dantec, N.; Beauverger, M.; Cuq, V.; Prunier, C.; Le Bivic, R.; Delacourt, C. Adequacy of pseudo-direct georeferencing of terrestrial laser scanning data for coastal landscape surveying against indirect georeferencing. Eur. J. Remote Sens. 2017, 50, 155-165. [CrossRef]

14. Floc'h, F.; Le Dantec, N.; Lemos, C.; Cancouët, R.; Sous, D.; Petitjean, L.; Bouchette, F.; Ardhuin, F.; Suanez, S.; Delacourt, C. Morphological Response of a Macrotidal Embayed Beach, Porsmilin, France. In Proceedings of the 14th International Coastal Symposium, Sydney, Australia, 6-11 March 2016; pp. 373-377.

15. Caulet, $C$. Les plages sableuses en environnement macro-tidal: De l'influence de la pente sur les processus morphodynamiques. Ph.D. Thesis, Université de Bretagne Occidentale, Brest, France, 2018. (In French).

16. Delacourt, C.; Allemand, P.; Jaud, M.; Grandjean, P.; Deschamps, A.; Ammann, J.; Cuq, V.; Suanez, S. DRELIO: An unmanned helicopter for imaging coastal area. J. Coast. Res. 2009, 56, 1489-1493.

17. Jaud, M.; Delacourt, C.; Allemand, P.; Grandjean, P.; Ammann, J.; Cancouët, R.; Deschamps, A.; Varrel, E.; Cuq, V.; Suanez, S. DRELIO: Un drone hélicoptère pour le suivi des zones littorales. In Proceedings of the XIèmes Journées Nationales Génie Côtier-Génie Civil (JNGCGC), Les Sables d’Olonne, France, 22-25 June 2010; pp. 485-496.

18. Dehouck, A.; Dupuis, H.; Sénéchal, N. Pocket beach hydrodynamics: The example of four macrotidal beaches, Brittany, France. Mar. Geol. 2009, 266, 1-17. [CrossRef]

19. Asseline, J.; De Noni, G.; Chaume, R. Note sur la conception et l'utilisation d'un drone lent pour la télédétection rapprochée. Photo-Interprétation Images Aériennes et spatiales 1999, 37, 3-13. (In French).

20. Jaud, M.; Grassot, F.; Le Dantec, N.; Verney, R.; Delacourt, C.; Ammann, J.; Deloffre, J.; Grandjean, P. Potential of UAVs for Monitoring Mudflats Morphodynamics (Application to the Seine estuary, France). Int. J. Geo-Inf. 2016, 5, 50. [CrossRef]

21. Lowe, D. Object recognition from local scale-invariant features. Proc. Int. Conf. Comput. Vis. 1999, 2, 1150-1157.

22. Eltner, A.; Kaiser, A.; Castillo, C.; Rock, G.; Neugirg, F.; Abellán, A. Image-Based Surface Reconstruction in Geomorphometry Merits-Limits and Developments. Earth Surf. Dyn. 2016, 4, 359-389. [CrossRef]

23. Tonkin, T.N.; Midgley, N.G. Ground-Control Networks for Image Based Surface Reconstruction: An Investigation of Optimum Survey Designs Using UAV Derived Imagery and Structure-from-Motion Photogrammetry. Remote Sens. 2016, 8, 786. [CrossRef]

24. Jaud, M.; Passot, S.; Allemand, P.; Le Dantec, N.; Grandjean, P.; Delacourt, C. Suggestions to Limit Geometric Distortions in the Reconstruction of Linear Coastal Landforms by SfM Photogrammetry with PhotoScan ${ }^{\circledR}$ and MicMac ${ }^{\circledR}$ for UAV Surveys with Restricted GCPs Pattern. Drones 2019, 3, 2. [CrossRef]

25. Javernick, L.; Brasington, J.; Caruso, B. Modeling the topography of shallow braided rivers using structure-from-motion photogrammetry. Geomorphology 2014, 213, 166-182. [CrossRef]

26. Masselink, G.; Castelle, B.; Scott, T.; Dodet, G.; Suanez, S.; Jackson, D.; Floc'h, F. Extreme wave activity during 2013/2014 winter and morphological impacts along the Atlantic coast of Europe. Geophys. Res. Lett. 2016, 43, 2135-2143. [CrossRef]

27. Scott, T.; Masselink, G.; O’Hare, T.; Saulter, A.; Poate, T.; Russell, P.; Davidson, M.; Conley, D. The extreme 2013/2014 winter storms: Beach recovery along the southwest coast of England. Mar. Geol. 2016, 382, 224-241. [CrossRef]

28. Garrote, J.; Díaz-Álvarez, A.; Nganhane, H.; Garzón Heydt, G. The Severe 2013-14 Winter Storms in the Historical Evolution of Cantabrian (Northern Spain) Beach-Dune Systems. Geosciences 2018, 8, 459. [CrossRef]

29. Blaise, E.; Suanez, S.; Stéphan, P.; Fichaut, B.; David, L.; Cuq, V.; Autret, R.; Houron, J.; Rouan, M.; Floc'h, F.; et al. Bilan des tempêtes de l'hiver 2013-2014 sur la dynamique de recul du trait de côte en Bretagne. Géomorphologie Relief Processus Environ. 2015, 21, 267-292. (In French). [CrossRef]

30. De Sanjosé Blasco, J.; Gómez-Lende, M.; Sánchez-Fernández, M.; Serrano-Cañadas, E. Monitoring Retreat of Coastal Sandy Systems Using Geomatics Techniques: Somo Beach (Cantabrian Coast, Spain, 1875-2017). Remote Sen. 2018, 10, 1500. [CrossRef] 
31. Suanez, S.; Cariolet, J.M.; Cancouët, R.; Ardhuin, F.; Delacourt, C. Dune recovery after storm erosion on a high-energy beach: Vougot Beach, Brittany (France). Geomorphology 2012, 139-140, 16-33. [CrossRef]

32. Turner, I.L.; Aarninkhof, S.G.J.; Dronkers, T.D.T.; McGrath, J. CZM Applications of Argus Coastal Imaging at the Gold Coast, Australia. J. Coast. Res. 2004, 20, 739-752. [CrossRef]

(C) 2019 by the authors. Licensee MDPI, Basel, Switzerland. This article is an open access article distributed under the terms and conditions of the Creative Commons Attribution (CC BY) license (http://creativecommons.org/licenses/by/4.0/). 